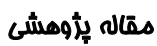

\section{ارتباط سبك زندكى با ير فشارى خون در كار كنان ادارات دولتى شهرستان بجنورد}

\author{
محسن صابر مقدم رنجبر'، رضوان رجب زاده ‘، داوود نصيرى زرين قبائى r**
}

أروه بيهوشى، دانشكده يزشكى، دانشكاه علوم يزشكى مشهد، مشهد، ايران

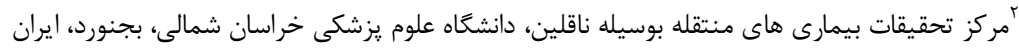

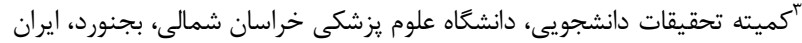

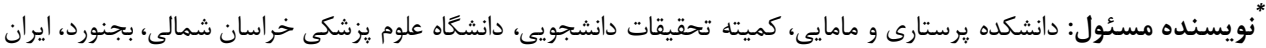

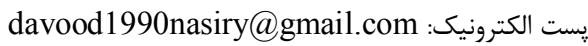
وصول:9r/F/T\&

زمينه و هدف: سبك زندكى زنجيره ایى يويا در تمام ابعاد زندكى انسان بوده نقش بسزايى در سلامتى افراد جامعه داردكه مى توان با

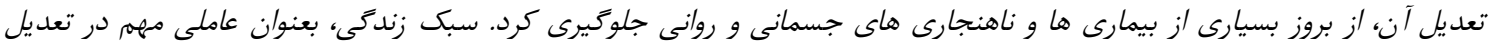

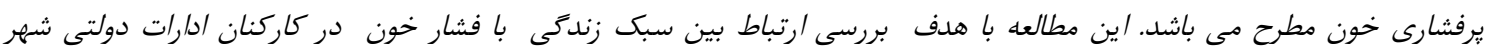
بجنورد انجام شد.

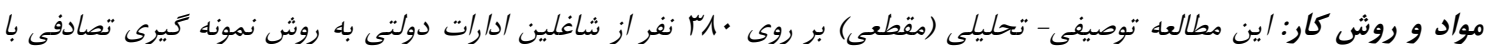

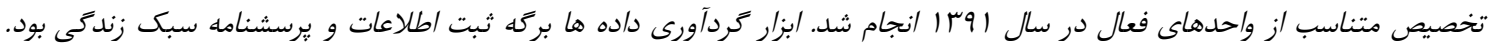

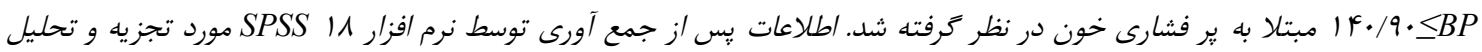

قرار كرفت.

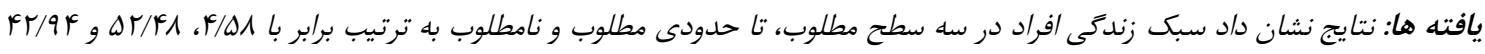

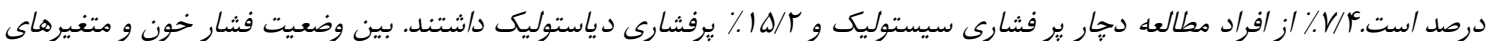

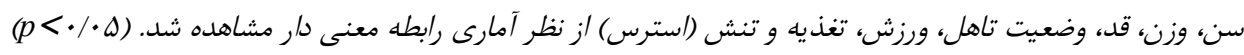

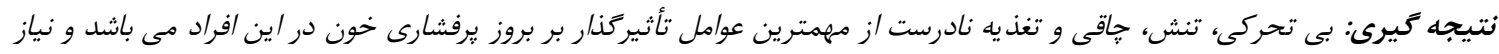

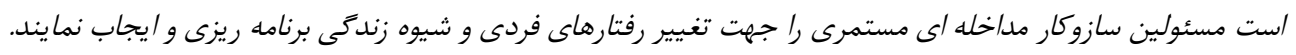

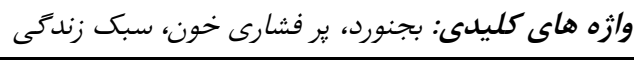

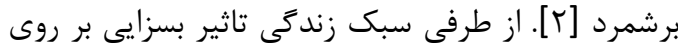
كيفيت زندگى و يیشگيرى از بيمارى ها دارد و براى حفظ

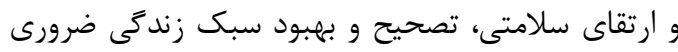
است، از اين جهت به عنوان يك ركن اساسى در زندگى هر فرد و ييشرفت جوامع مورد توجه قرار مى گيرد [ب].

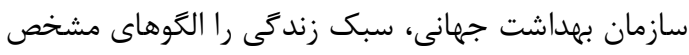
وقايع رفتارى مى داند كه از تعامل بين ويزَى هاى شخصى، روابط اجتماعى، شرايط محيطى و موقعيت هاى

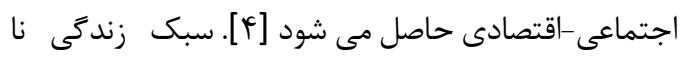

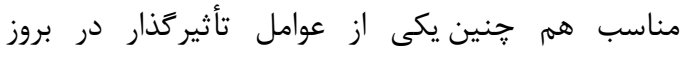

مقدمه سبك زندگىى، فعاليت عادى و معمول روزمره مى باشد كه

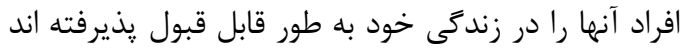

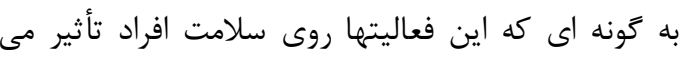
كذارند [1]. فرد با انتخاب سبك زند زئى سالم براى حفظ و ارتقاى سلامتى خود و ريشخيرى از بيماريها، اقدامات و فعاليت هايى از قبيل رعايت رزيم غذايى صحيح، خواب و فعاليت، ورزش، كنترل وزن بدن، عدم مصرف سيگار و و الكل و ايمن سازى در مقابل بيماريها را انجام مى دهد كه اين مجموعه را مى توان از ابعاد مختلف سبكى زندىى دئى 
زندگى و يرفشارى خون در ساكنين YF-9D ساله منطقه كوثر شهر قزوين انجام شد، نتايج مطالعه نشان داد داد

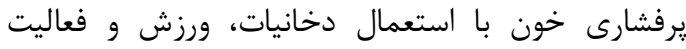
فيزيكى و شاخص توده بدنى، ارتباط معنى دار آمارى

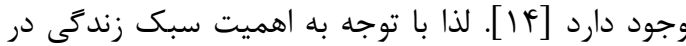
زندگى افراد و تاثير بسزايى كه در پِيشكيرى از بيمارى ها إنا

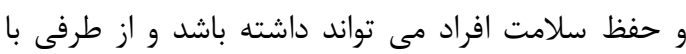
توجه به افزايش روز افزون شمار مبتلايان به بيمارى مزمن

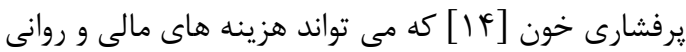

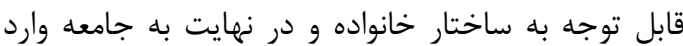
نمايد، يزوهشكَران درصدد برآمدند تحقيقى در اين زمينه

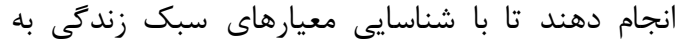

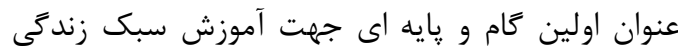

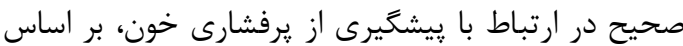

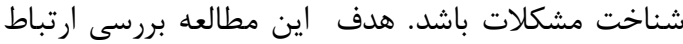
بين سبك زندگى با يرفشارى خون در كاركنان ادارات دولتى شهرستان بجنورد مى باشد. روش كار اين مطالعه توصيفى- تحليلى (مقطعى) بعد از دريافت

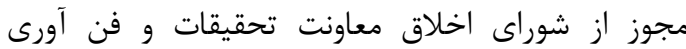

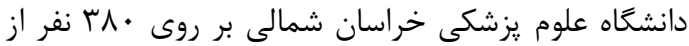

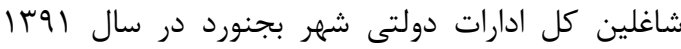

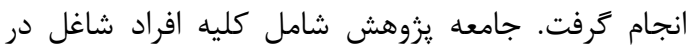
ادارات دولتى شهر بود كه داراى شرايط انتخاب شدن بودند (فعاليت حداقل روزانه يك شيفت كارى در بـ ماه اخير داشتند، نبايد طى يك ساعت قبل از اندازه كيرى

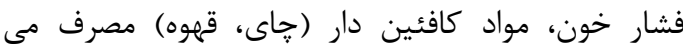
كردند و حداقل از ها دقيقه قبل از اندازه كيرى فشار

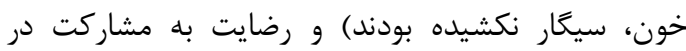
انجام يزوهش داشتند. روش نمونه كيرى در اين يزوهش، نمونه گيرى تصادفى با تخصيص متناسب از واحدهاى

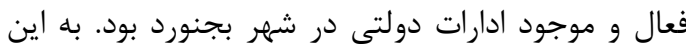

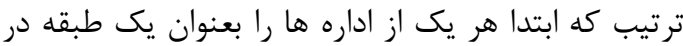

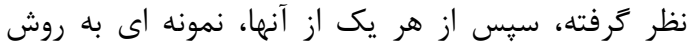

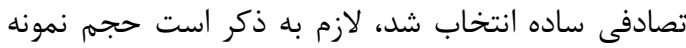

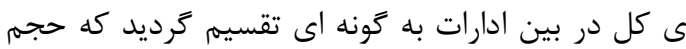
نمونه ى انتخاب شده از هر يك از طبقات ( اداره ها)
بيمارى هاى مزمن از جمله سرطان كولون،فشارخون

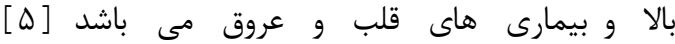
يكى از مهمترين و عمده ترين علل مرك و مير مئر در ايران،

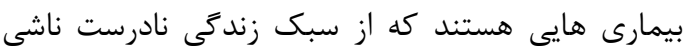

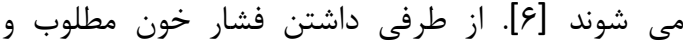

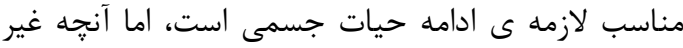

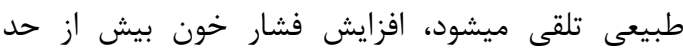
طبيعى در بدن است. افزايش فشار خون با خطر مركى و

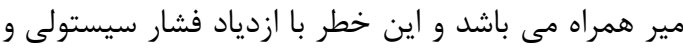

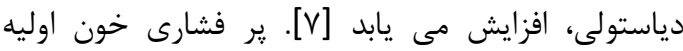

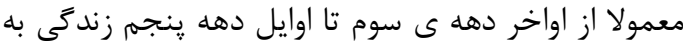
صورتى نايايدار شروع مى شود و بالاخره وضعيت ثابتى

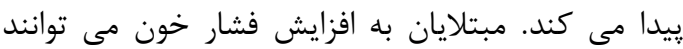

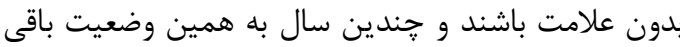
بمانند. شيوع بيشتر ير فشارى خون در افراد بالاى لهائ سال به افزايش فشار خون سيستولى مربوط مى شئن شود.

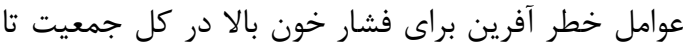

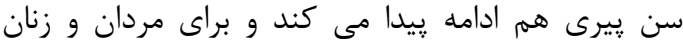

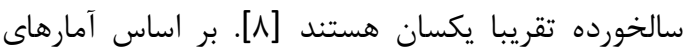

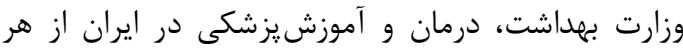

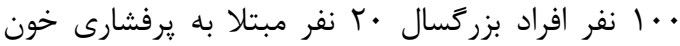

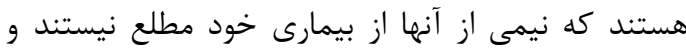

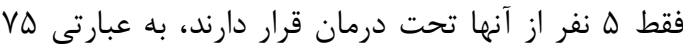
درصد افراد مبتلا به فشار خون درمان نمىشوند إند و اين مسئله فقط منحصر به ايران نيست بلكه كشورهاى קيشرفته نيز فشار خون بالاى درمان نشده دارند. از اينرو

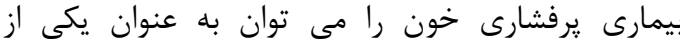

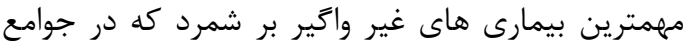

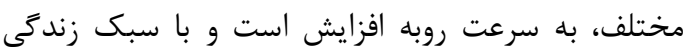
افراد ارتباط نزديكى دارد [ه، 9]. در :يزوهشى كه منصوريان و همكاران تحت عنوان ارتباط بين سبك دريك زندگى با يرفشارى خون در جمعيت روستايى شهرستان كركان انجام دادند، نتايج مطالعه نشان داد داد كه تفائ معنى دارى بين سبك زندگى با فعاليت بدنى، رشد

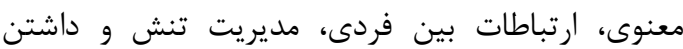

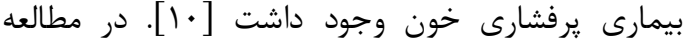

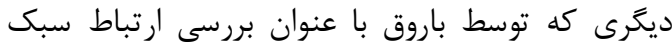


قبل از شروع براى همه ى واحد هاى يزوهش تشريح شد.

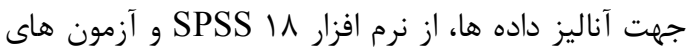
كروسكال واليس و ضريب همبستگى پيرسون در سطح معنى دارى ه • • • استفاده كرديد.

يافته ها

نتايج مطالعه نشان داد 99/V٪ شركت كنندگان مرد و

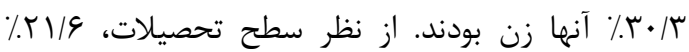

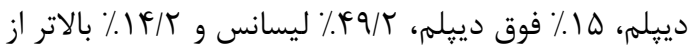

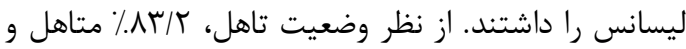

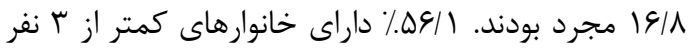

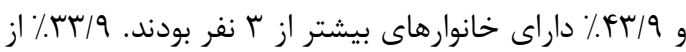
واحدهاى يزوهش داراى سابقه خانوادگى بيمارى فشار

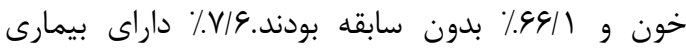

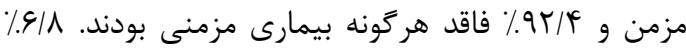

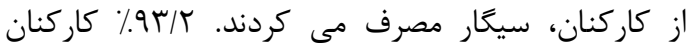

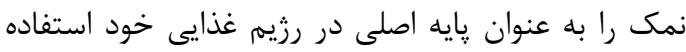

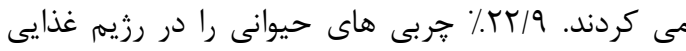

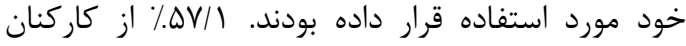

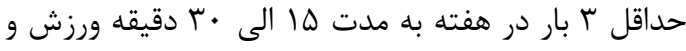

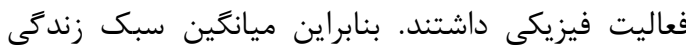
افراد مورد مطالعه در ب سطح مطلوب، تاحدودى مطلوب و و نامطلوب بترتيب برابر با

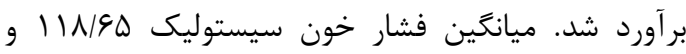
ميانكين فشار خون دياستوليك واحد هاى يزوهش ه ه

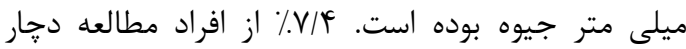

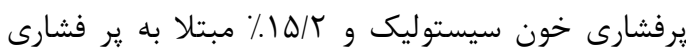
خون دياستوليك بودند. بين وضعيت تاهل با فشار خون

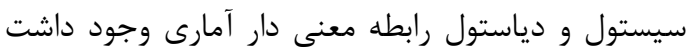
(p) بطوريكه فشار خون سيستول افراد متاهل بيش از افراد مجرد بود. بين ورزش و فعاليت فيزيكى با بالهار فشار خون دياستولى ارتباط معنى دار آمارى مشاهده شد

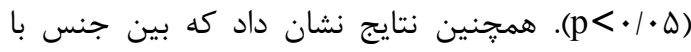
فشار خون سيستول و دياستول و همجنين سابقه فاميلى، ناني،

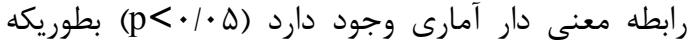

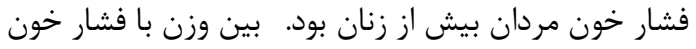

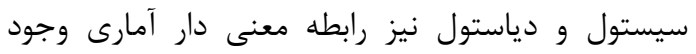

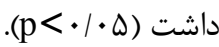

متناسب با تعداد كاركنان آن اداره باشد. ابزار كردآورى اطلاعات، يرسشنامه دو قسمتى مشخصات دموكرافيكى و

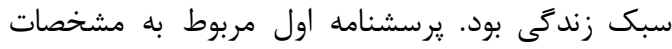
فردى شاغلين (سن، جنس، سطح تحصيلات، وضعيت

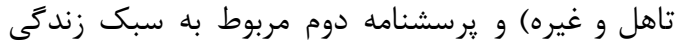

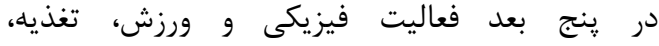

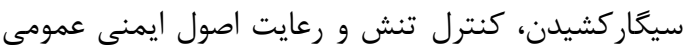

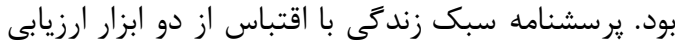

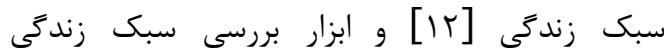

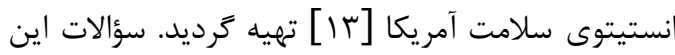
ابزار در له قسمت مربوط به ينج بعد سبك زندكى بود و

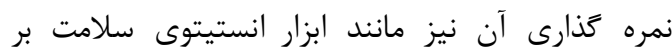

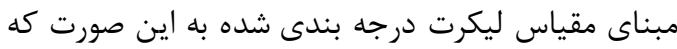

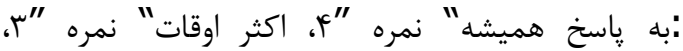

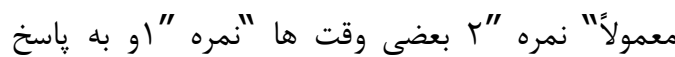

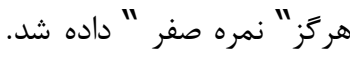

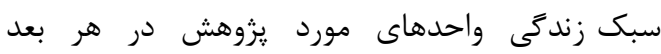

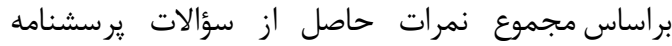

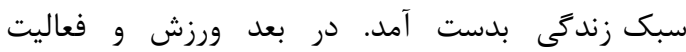

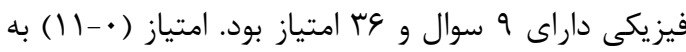

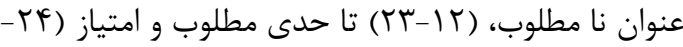
عَ) به عنوان مطلوب در نظر ترفته شد. در بعد تغذيه

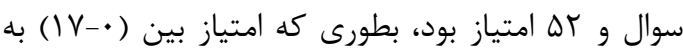

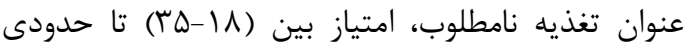

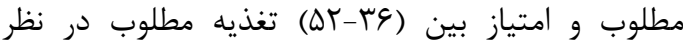

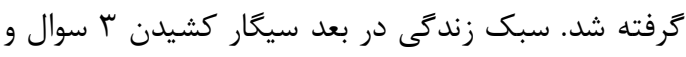

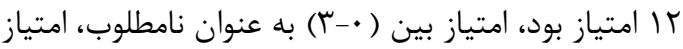

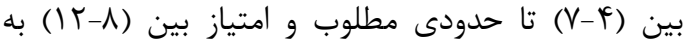

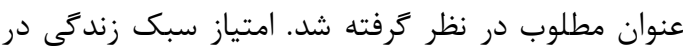

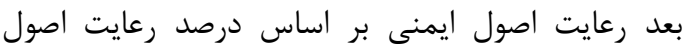

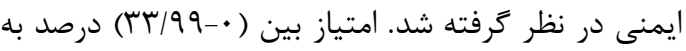

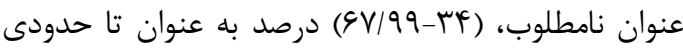

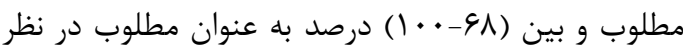
كَرفته شد. سبك زندَى در بعد كنترل تنش 11 سوال و

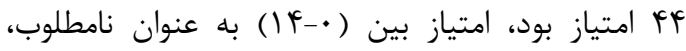

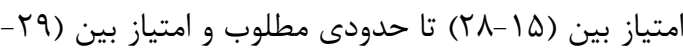

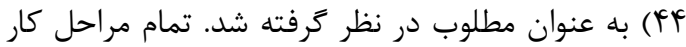


جدول ا: فراوانى ابعاد سبك زندگى در واحدهاى مورد يزوهش

\begin{tabular}{|c|c|c|c|}
\hline نامطلوب & تا حدودى & مطلوب & ابعاد سبك زندگى \\
\hline فراوانى (درصد فراوانى) & فراوانى (درصد فراوانى) & فراوانى (درصد فراوانى) & \\
\hline$(Y r / q) q 1$ & $(\Delta G / Y) Y / F$ & $(19 / V) \vee \Delta$ & 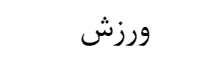 \\
\hline$(V \& \mid q) Y q 1$ & $(Y T / Y) \Lambda \Lambda$ & $(\cdot / /))$ & ايمنى \\
\hline$(\mathcal{F} / \mathcal{F})|\varepsilon|$ & $(\Delta \varphi / \varphi) Y \mid \Delta$ & $(1 / 1)^{f}$ & تغذيه \\
\hline$(\Delta \Delta / \Delta) r \|$ & $(F T / Q) \backslash \varepsilon r$ & $(1 / 9) 9$ & 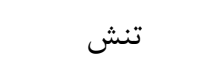 \\
\hline$(19 / T) g r$ & $(\Lambda r / \Psi) r \mid V$ & $(\cdot)$. & سيعار \\
\hline
\end{tabular}

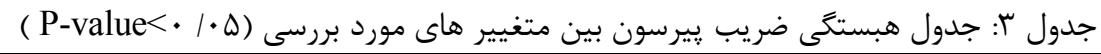

\begin{tabular}{|c|c|c|c|c|c|c|c|c|c|}
\hline تنش & سيخار & تغذيه & ايمنى & ورزش & فشار خون & فشار خون & سن & & \\
\hline & $\cdot|/ \wedge|^{* * * *}$ & $-\cdot / \cdot r \Lambda$ & $-\cdot 1 \cdot 4 q$ & $\cdot / \cdot \Delta \cdot$ & $\cdot / T \Delta r^{* * * *}$ & $\cdot / r \Delta r^{* * * *}$ & 1 & ضريب پيرسون & سن \\
\hline $.1 \cdot 1$ & $\cdot 1 \cdots$ & $\cdot / 4 \& D$ & גזس/. & ا וזس|. & $\cdot 1 \cdot \cdots$ & $\cdot 1 \cdot \cdots$ & & $\mathrm{P}$ value & (سال) \\
\hline$\cdot 1111^{*}$ & •lerv & $\cdot / 1 \cdot r^{*}$ & /. & $.1 \cdot r \Delta$ & $\cdot 19 \wedge D^{* * *}$ & 1 & & ضريب پيرسون & فشار خون \\
\hline$\cdot 1 \cdot T V$ & $\cdot / \& V$. & $.1 \cdot$ et &.$/ 9 V F$ & $.19 r \wedge$ & $\cdot 1 \cdots$ & & & $\mathrm{P}$ value & سيستول \\
\hline .1 .91 & $\cdot 1 \cdot V \Delta$ & $\cdot 1 \cdot 9$. & $\cdot 1 \cdot 9$. & $\cdot 1 \cdot 4 q$ & 1 & & & ضريب پيرسون & فشار خون \\
\hline . &.$/ 1 \mathrm{FV}$ & $\cdot \mid \cdot 11$ & - Mpf & . $|M F|$ & & & & $P$ value & $\begin{array}{l}\text { دياستول } \\
\text { (mmHg) }\end{array}$ \\
\hline
\end{tabular}


ضمن مراقبـت و وِيثـَيرى از بـروز ايـن بيمـارى، سـبك

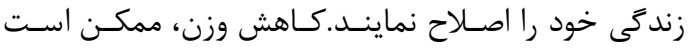

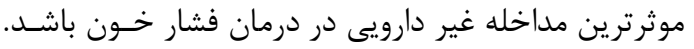

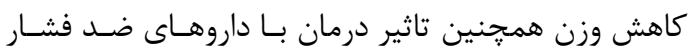

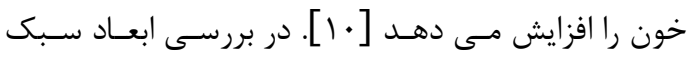

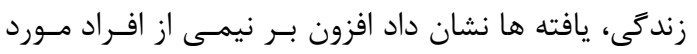

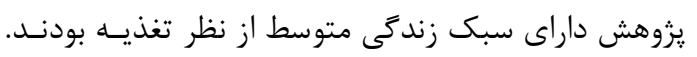

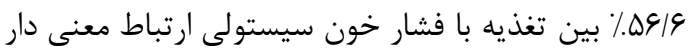

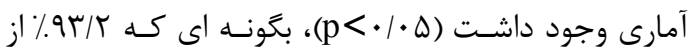

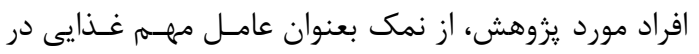
برنامه تغذيه اى خود استفاده مى كردند، كه اين يافتـهـ بـ بـا

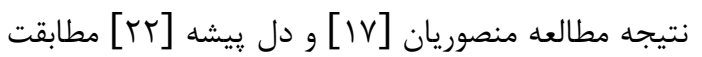

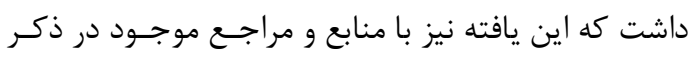

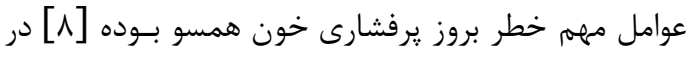

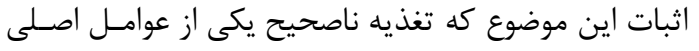

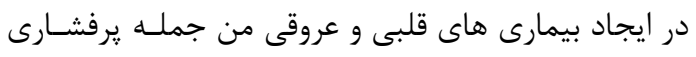

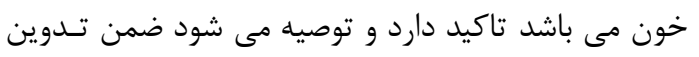

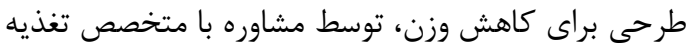

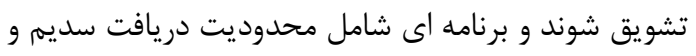

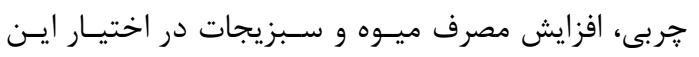

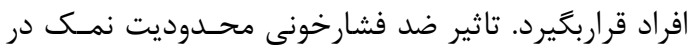

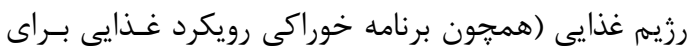
توقف افزايش فشار خون موجب كاهش انـدى امــا بايــدار

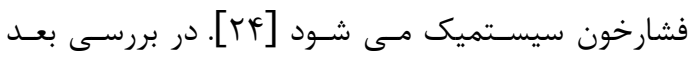

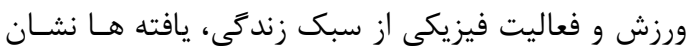

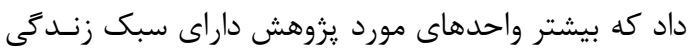

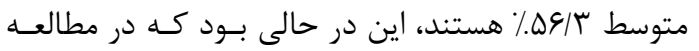

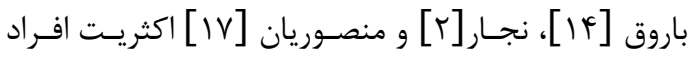

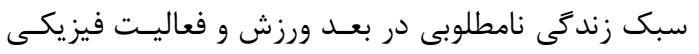

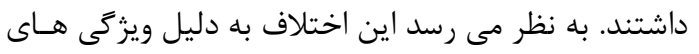

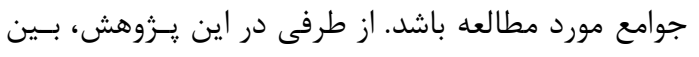

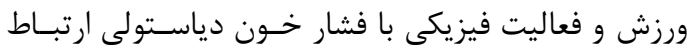

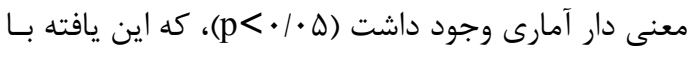

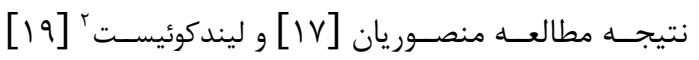

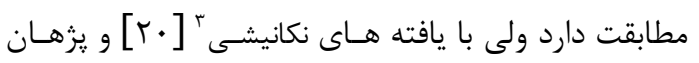

2- Lindquist 3 -Nakanishi
سبك زندگى بايد به صورت يك تركيب يِيجيده اى از

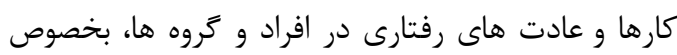

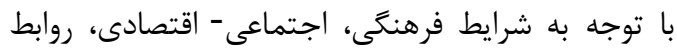

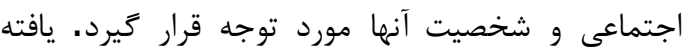

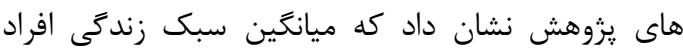

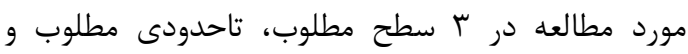

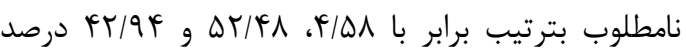
است كه بين سبك زندكَى در بعد تغذيه و تنش با با فشار

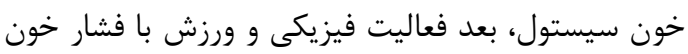

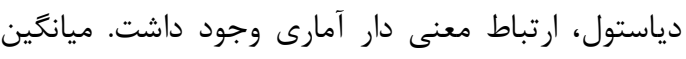

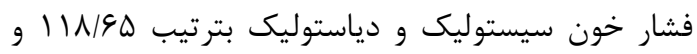

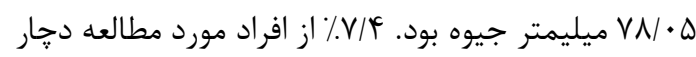

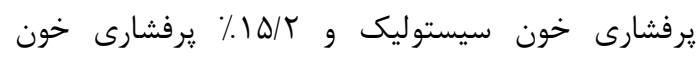

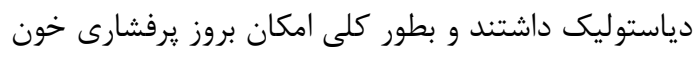

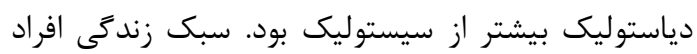
مورد مطالعه نيز تا حدودى مطلوب برآورد شد.

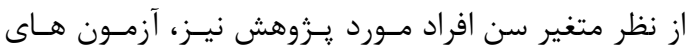

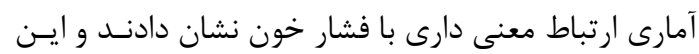

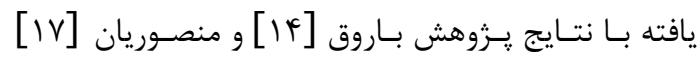

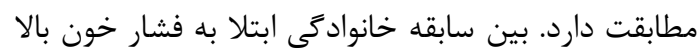

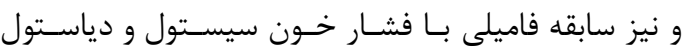
رابطه معنى دار آمارى وجود داشت. كه اين نتيجه با يافتئه

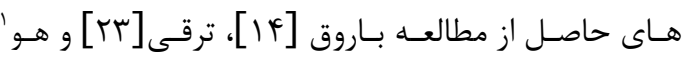

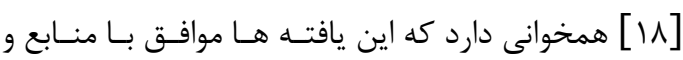

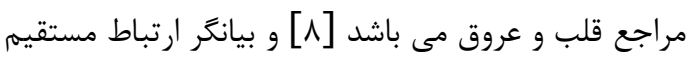

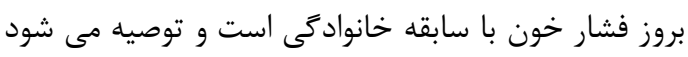

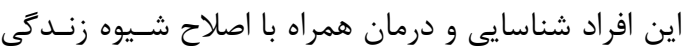

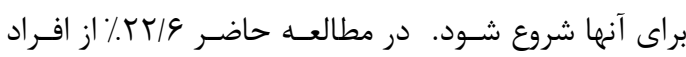

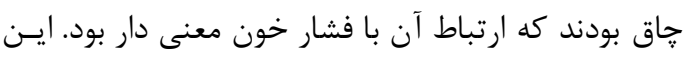

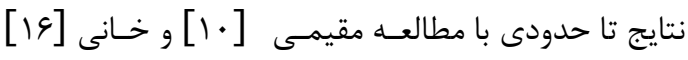

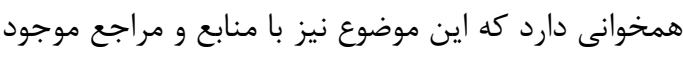

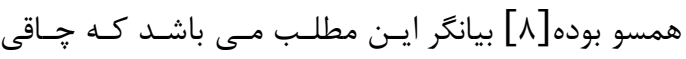

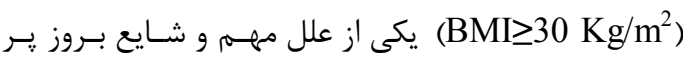
فشارى خون ثانويه مى باشد و توصيه مى شود ايسن افـراد

$1-\mathrm{Hu}$ 


$$
\begin{aligned}
& \text { تنش، مانع از بروز و يا كاهش آن و در نتيجه جلوكيرى از } \\
& \text { بروز بيمارى هاى متعاقب آن همجِون فشار خون كردند } \\
& \text { نتيجه كيرى } \\
& \text { در اين يزوهش يافته ها نشان مى دهند كه مهرمترين } \\
& \text { عوامل وجود بيمارى يرفشارى خون، عادت هاى رفتارى ئرى } \\
& \text { غلط و نامناسب بخصوص در زمينه مصرف نمك، غذاهاى }
\end{aligned}
$$

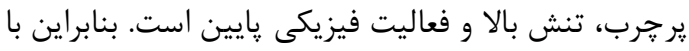

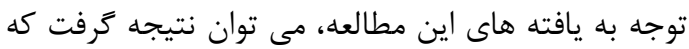

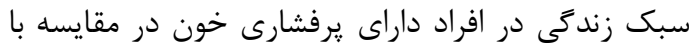

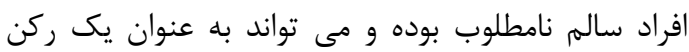

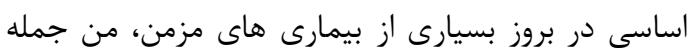

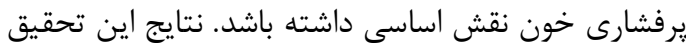

$$
\begin{aligned}
& \text { مى تواند براى مراقبين سيستم بهداشت و درمان اين ائنان } \\
& \text { استان و نيز سيستم هاى مديريتى ادارات كمك كنيندا }
\end{aligned}
$$

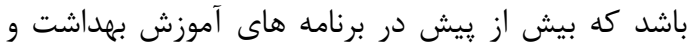

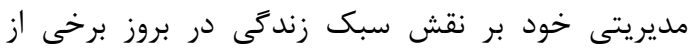

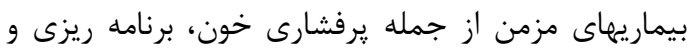

$$
\begin{aligned}
& \text { تاكيد داشته باشند. }
\end{aligned}
$$

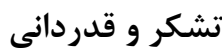

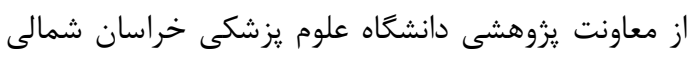

$$
\begin{aligned}
& \text { كه در انجام هماهنكى هاى لازم با ادارات و نيز تأمين }
\end{aligned}
$$

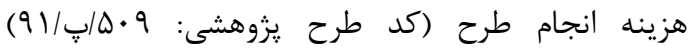

$$
\begin{aligned}
& \text { مساعدت لازم را مبذول داشتند تقدير و تشكرمى نمائيم. }
\end{aligned}
$$

\section{References}

1. Lyons R, Langille L, Healthy Lifestyle: Strengthening the effectiveness of lifestyle, Approaches to improve health: 2008;22(7): 186- 209.

2. Najar L, Haidai A, Behnam Vashani B, The Relationship between lifestyle and essential hypertension in Sabzevar, Journal of Sabzevar University of Medical Sciences, Asrar 2005; 11(2) 49-55[Persian].

3. Mohamadi Zaid E, Haidar Nia A, Hejizadeh E, [Lifestyle of patients with cardiovascular in Chabahar], Daneshvar Medicine Journal 2006; 61(3) 49-56[Persian]. 4. Gro HB, World Health Organization reducing risk, promoting health, World Health Report, Geneva. WHO. 2009;URL: http://www.who.net : (Accessed:9 march 2009)
[Tl [ مغايرت داشت. به نظر مى رسد اين اختلاف مربـوط

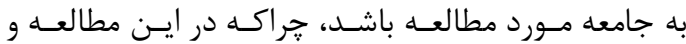

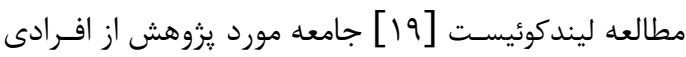

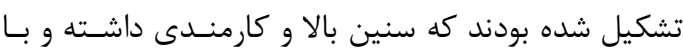
توجه به مشغله هاى كارى روزمره از حداقل فعاليت هـاى داى دالي

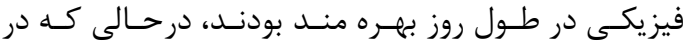

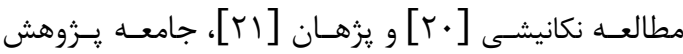
بصورت عمومى و از بين تمام مردم سطح شهر كرفته شده

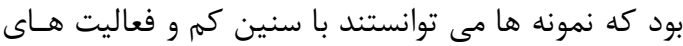
فيزيكى بالا بعلت دوره زمانى سنى خود وارد مطالعه شوند.

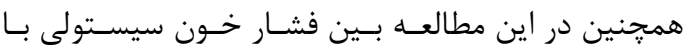

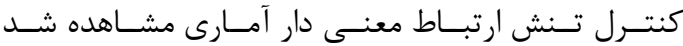

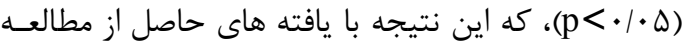

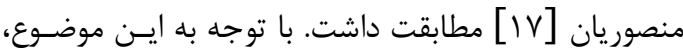

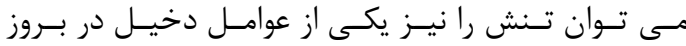

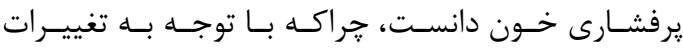

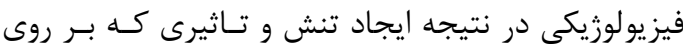
عروق و جريان فشار خون دارد، در طولانى مـدات و تــنش هاى مداوم احتمالا مى تواند در ايجاد اين اين بيمارى درى دخالت

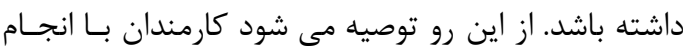

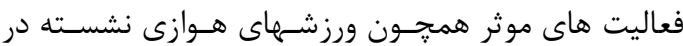
زمان استراحت هاى روزمره در بين ساعات كارى و مشاوره با روانشناس و بهره كيرى از اصول صحيح كاهش و كنترل

5. Taghdici M, Doshmangir $\mathrm{P}$, Dehdari $\mathrm{T}$, Doshmangir L, Influencing factors on healthy lifestyle from viewpoint of elderly people: qualitative study, Iranian Journal of Ageing 2013; 7 (27) :0-0.

6. Azizi F, Prevention of important non communicable disease, revision of lifestyle is an inevitable requirement, J Res Med Sci Shahid Beheshti Univ Med Sci .2004;27(4):261-263[Persian].

7. Azizi A, Abasi M, Abdoli GH, The prevalence of hypertension and its association with age, sex and BMI in a population being educated using community-based medicine in Kermanshah, Iranian Journal of Endocrinology \& Metabolism 2008; 10(4) 323-330[Persian]. 8. Brunner \& Suddarth's, Textbook of medical Surgical nursing; $11^{\text {th }}$ ed. C 2008. 
9. Moghimi M, Salari M, Abasi A, Saniee F, Nemati F, Survey of hypertension and related risk factors in Yasoj elderly people, Dena Journal 2007; 1(2) 65-71[Persian].

10.Moghimi M, Salari M, Abasi A, Saniee F, Nemati F, [Survey of hypertension and related risk factors in Yasoj elderly people], Dena Journal 2007; 1(2) 65-7111[Persian]. 11.Najjar L, Heydari A,BehnamVashani HR, The relationship between lifestyle and essential hypertension in Sabzevar, Iran, J Sabzevar Univ Med Sci. 2004;11(2):49-54[Persian]. 12.Rozmus C , Evans R , Wysochansky M., Mixon D, An analysis of health promotion and risk behaviours of fresh man college students in a rural 791outhern setting, J Pediatr Nurs; 2005.20(1): 25-32.

13.Brukner FPA, Endocrinologic condition in medical problems, Athletes: Black well Scince; 2003. P.216.

14.Baroogh N, Teimouri F, Saffari M, Hosseini S S, Mehran A, Hypertension and lifestyle in 24-65 year old people in Qazvin Kosar region in 2007; Journal Shahid Beheshti University of Medical Sciences, 2009: 15(5), p 193-198[Persian].

15.Faragzadeh Z, Kaheni S, Saadatjoo A, Relation between stress and hypertension and coping ways, J Birjand Univ Med Sci 2005;12(1,2):9-15.

16.Khani M, Vakili M, Ansari A, Prevalence of hypertension and some related risk factors in rural population affiliated to Tarom health center in 2001, Sci J Zanjan Univ Med Sci 2002;40:23-9[Persian].

17.Mansourian M, Qorbani M, Shafieyan N, Asayesh H, Rahimzadeh Barzaki H, Zainab Shafieyan, Arefi Rad T, Maghsodlo D, Association between life style and hypertension in rural population of Gorgan, Journal Of Health Promotion Management.
ISSN:2251-8614, Vol:1. No:2, Spring 2012[Persian].

18. Hu G, Tian H, A comparison of dietary and non-dietary factors of hypertension and normal blood pressure in a Chinese population, J Hum Hypertens 2001;15(7):487-93.

19.Lindquist TL, Beilin LJ, Knuiman MW, Influence of lifestyle, coping, and job stress on blood pressure in men and women, Hypertension 1997;29(1 Pt 1):1-7.

20.Nakanishi N, Nakamura K, Ichikawa S, Suzuki K, Tatara K, Lifestyle and the development of hypertension: a 3-year followup study of middle-aged Japanese male office workers, Occup Med (Lond) 1999;49(2):10914.

21.Pejhan A, Najjar L, Heydari A, Hajeezadeh $\mathrm{S}$, Rakhshani $\mathrm{M}$, The status of blood pressure in urban population of Sabzevar in 1382, J Rafsanjan Univ Med Sci 2005;4(2):95102[Persian].

22.Delpishe A, Saye Miry K, Blood pressure status of workers over 40 years of Ilam and its association with body mass index and lifestyle; Journal of Ilam University of Medical Sciences;2002,9(33-34).P 11-17.

23.Taraghi Z, Ilali A.; Screening for hypertension in truck drivers, Hayat Journal 2005;21(9) 63-69.

24. Stoelting's anesthesia and co-existing disease, $5^{\text {th }}$. ed, c2008.

25.Choudhury S.R and okayama;The association between alcohol drinking and dietary habits and B.P in Japanese ,men; Journal of Hypertension13(6).p.p 587-593. 26. Raquel V. Patricia M K. Perry I, The cumulative effect of core lifestyle behaviors on the prevalence of hypertension and dyslipidemia, BMC Public Health 2008; 8(7) 2-10. 
Original Article

\title{
Relationship of lifestyle and Hypertension in administrative employees in Bojnourd rural areas
}

\author{
Saber Moghadam Ranjbar $M^{l}$, Rajabzade $R^{2}$, Nasiry Zarin Ghabaee $D^{3 *}$ \\ ${ }^{1}$ Department of Anesthesiology, School of Medicine, Mashhad University of Medical Sciences, Mashhad, Iran \\ ${ }^{2}$ Vector-borne Diseases Research Center, North Khorasan University of Medical Sciences, Bojnourd, Iran \\ ${ }^{3}$ North Khorasan University of Medical Sciences, Bojnourd, Iran
}

*Corresponding Author: Student Research Committee, North Khorasan University of Medical Sciences, Bojnourd, Iran

Email: davood1990nasiry@ gmail.com

\begin{abstract}
Background and Objectives: Life style is composed of a chain of active parameters in all dimensions of human life and has a substantial impression on health of population. Since vast majority of health problems has a strong relationship to life style, occurrence of many somatic and psychological disorders would be prevented provided that life style rectified.

Blood pressure is one of the most important health criteria moderated when life style has been changed. The aim of this investigation was to study the cause_effect relationship of life style and blood pressure in administrative employees in Bojnurd rural areas.

Materials and Methods: In this descriptive-analytical (cross sectional) study 380 cases of governmental administrative employees were selected on a stratified random sampling with proportional allocation basis. The Study was conducted on 2012 in Bojnourd city of Iran. Primary data gathering tools were data recording sheet and lifestyle questionnaire.

$B P \geq 90 / 140$ were considered as hypertensive. The data analyzed in SPSS software. (V18)

Results: The life style in 3 levels of desirable, relatively desirable and undesirable estimated to be 4.58, 52.48 and 42.94 respectively. $7.4 \%$ of those studied suffered from high systolic blood pressure and $15.2 \%$ had diastolic hypertension. Blood pressure was significantly related to age, weight, height, marital status, exercise, nutrition, stress and body mass index.

Conclusions: stress, malnutrition and obesity are among the factors influencing the incidence of hypertension. The essence of implementation of ongoing intervention programs by official bodies to change individual behaviors and lifestyle seems to be required.

Keywords: Bojnurd, Hypertension, Lifestyle
\end{abstract}

Submitted: 17 July 2013

Revised:20 Nov 2013

Accepted: 7 Dec 2013 